\title{
A TEORIA SOCIAL DE NORBERT ELIAS E SUAS CONTRIBUIÇÕES PARA A SOCIOLOGIA DO PODER
}

\section{The Social Theory of Norbert Elias and his Contributions to the Sociology of Power}

Natália Cristina Granato ${ }^{1}$

\begin{abstract}
RESUMO: No presente artigo, assinalaremos as linhas gerais do pensamento sociológico de Norbert Elias e suas conexões com a sociologia histórica do poder desenvolvida ao longo de sua obra. Esperamos contribuir com uma possível análise do poder nas sociedades contemporâneas a partir de seus pressupostos teórico-metodológicos. A obra de Norbert Elias permite pensar o poder de maneira relacional, estrutural e configuracional. Pensar o poder também nos leva a reflexão histórica e estrutural das instituições e dos indivíduos, proporcionando importantes bases para a análise social e política.
\end{abstract}

PALAVRAS-CHAVE: Sociologia do poder; Teoria social; Norbert Elias; Família; Política.

ABSTRACT: In this paper, we will point out the general lines of Norbert Elias' sociological thinking and his connections with the historical sociology of power developed throughout his work. We hope to contribute to a possible analysis of power in contemporary societies based on their theoretical and methodological assumptions. The work of Norbert Elias allows us to think about power in a relational, structural and configurational way. Thinking power also leads us to the historical and structural reflection of institutions and individuals, providing important bases for social and political analysis.

KEYWORDS: Sociology of Power; Social Theory; Norbert Elias; Family; Politics.

No presente artigo, assinalaremos as linhas gerais do pensamento sociológico de Norbert Elias e suas conexões com a sociologia histórica do poder desenvolvida ao longo de sua obra. Este texto é resultado de uma apresentação no Curso de Extensão "Teoria Social para estudos de Família, Política e Parentesco", na qual o autor analisado foi o sociólogo alemão Norbert Elias. Esta apresentação ocorreu no dia 14 de abril de 2018, nas dependências da Universidade Federal do Paraná.

\footnotetext{
${ }^{1}$ Doutoranda em Sociologia pela Universidade Federal do Paraná (UFPR) e professora na Secretaria de Estado da Educação do Paraná (SEED-PR). E-mail: nataliagranato@hotmail.com
} 
Norbert Elias nasceu em Breslau, no antigo território alemão em 1887. De família judaica, era filho de Hermann Elias e Sophie Elias. Sua mãe foi vítima de um campo de concentração nazista e sua família foi perseguida durante muitos anos de sua vida. Nestes percalços, formou-se em Filosofia e Medicina. Sua aproximação com a Sociologia se deu a partir de 1925, com grande proximidade à figura intelectual de Karl Mannheim. Sua obra, porém, só obteve reconhecimento internacional a partir da década de 1970.

Entre as suas principais obras, destacam-se os dois volumes de "O Processo Civilizador", além de "A Sociedade dos Indivíduos", "Norbert Elias por ele mesmo", "Os alemães", "Mozart, a Sociologia de um gênio", "A Sociedade de Corte", "Sobre o Tempo" e "Os Estabelecidos e os Outsiders", todas publicadas no Brasil pela Editora Zahar.

Destacamos que a obra de Norbert Elias apresenta como principais questões a análise das formas de interação e do significado que as estruturas adquirem em configurações sociais específicas que interferem nas personalidades individuais e nas estruturas sociais. Tal entendimento é relacionado à ideia de que os indivíduos não são totalmente livres ou autônomos, principalmente devido ao aumento da cadeia de interdependências recíprocas entre os mesmos. As relações estabelecidas entre os indivíduos nas figurações e estruturas sociais, bem como personalidades individuais, não foram planejadas por eles, nem se desenrolaram de maneira caótica e desordenada ${ }^{2}$. Tentaremos, no presente trabalho, demonstrar uma ideia básica do que são estes conceitos, tentando articulá-los com a sociologia do poder e da política.

\section{Algumas considerações sobre a relação entre o indivíduo e a sociedade em Norbert Elias}

A obra de Norbert Elias é um dos principais destaques para o desenvolvimento da sociologia contemporânea no decorrer do século XX. No século anterior à esta produção, a sociologia clássica foi reconhecida nas obras de seus precursores Émile Durkheim, Karl Marx e Max Weber, expoentes da consolidação deste campo de conhecimento enquanto ciência, com teorias e métodos próprios. Estes autores foram responsáveis por um novo e inédito olhar sobre o social, fundamental para a institucionalização da Sociologia. Os três autores debateram criticamente com escolas de pensamento filosóficas dominantes

\footnotetext{
${ }^{2}$ RIBEIRO, Luci Silva. Processo e figuração: um estudo sobre a Sociologia de Norbert Elias. Tese. Doutorado em Sociologia. Universidade de Campinas, 2010, p. 169-171.
} 
nos debates acadêmicos do século XIX e do início do século XX, estabelecendo novos paradigmas de compreensão da realidade. No entanto, na formação da Sociologia, visualizamos o embate entre teorias que privilegiam o social em detrimento do individual (especialmente visível nas obras de Durkheim e Marx), e o objetivismo em detrimento do subjetivismo. Segundo Philippe Corcuff, tais pares conceituais foram herdados da Filosofia, fazendo, muitas vezes, com que os pesquisadores escolham um dos campos dicotômicos e binários sem superá-los ${ }^{3}$.

Em contraposição a estes binários, "as novas sociologias" se colocam sob uma perspectiva construtivista, na qual a realidade social é aprendida como uma construção histórica e cotidiana dos atores individuais e coletivos ${ }^{4}$. A obra de Elias significa uma ressignificação das teorias clássicas sob novos paradigmas, através de pesquisas que dialogam a teoria e a empiria na análise social. O autor também estabelece novos olhares sobre a relação entre o indivíduo e a sociedade, com uma obra de grande valia à pesquisa sociológica.

Nesse ponto de vista, Philippe Corcuff aponta que Elias, entre outros autores da sociologia contemporânea, desenvolve seus trabalhos sob uma perspectiva construtivista de dialogar os pares dicotômicos objetivo/subjetivo e coletivo/individual, combinando estruturas sociais a dimensões subjetivas e interacionistas.

A obra do sociólogo alemão Norbert Elias destaca-se, segundo Corcuff, pelo diálogo entre o teórico e o empírico, perceptivo no livro de sociologia do conhecimento "Envolvimento e alienação", na qual o autor reconhece que os objetos são ao mesmo tempo sujeitos, que produzem representações sobre a vida em sociedade, ao mesmo tempo em que os pesquisadores são também parte do objeto de estudo ${ }^{5}$. Elias também se coloca contra a dicotomia entre o indivíduo e a sociedade, assinalando a interdependência entre ambos. Um exemplo desta postura teórica pode ser visualizado na obra "O Processo Civilizador", na qual Elias procura entender a História como diacrônica, um longo trajeto que se estende ao longo dos séculos, com avanços e recuos ${ }^{6}$.

Um dos principais raciocínios desenvolvidos pelo autor nesta obra é o reconhecimento deste processo como gerador de mudanças na conduta e nos sentimentos humanos que

\footnotetext{
${ }^{3}$ CORCUFF, Philippe. As Novas Sociologias: Construções da realidade sociais. Queluz: Editora Vral, 2001, p. 11-12.

${ }^{4}$ Ibid., p. 22.

${ }^{5}$ Ibid., p. 28.

${ }^{6}$ RIBEIRO, Renato Janine. Apresentação a Norbert Elias. In: ELIAS, Norbert. O processo civilizador. Volume I. Rio de Janeiro: Zahar, 1994a.
} 
não foi planejada intencionalmente por indivíduos isolados, nem se desenrolou de maneira caótica e desestruturada, mas ocorreu através da interdependência entre seres humanos entrelaçados, dependentes mutualmente e em constante movimento. Esta mudança ocorreu na estrutura das relações humanas e também nas estruturas de personalidade $^{7}$. O processo civilizador leva o indivíduo a regular sua conduta de maneira diferenciada, uniforme e estável ${ }^{8}$, que ocorre de maneira consciente e inconsciente. $\mathrm{O}$ autocontrole e a regulação geram a estabilização das pulsões no nível individual e estrutural, conforme o demonstrado por Elias quando o mesmo analisa a constituição do Estado, órgão processualmente centralizado e estabilizado. Tal processo aconteceu com a monopolização da força física por parte deste aparelho. A "pacificação" promovida por este processo gera no indivíduo a proteção contra os ataques súbitos de violência que atentam à sua própria vida, mas internamente provoca em si mesmo a repressão de "qualquer impulso emocional para atacar fisicamente outra pessoa"9. O processo civilizador desafia o indivíduo a controlar suas paixões, impulsos e emoções para garantir seu prestígio social.

Tal olhar sobre o social e seus aparatos sociogênicos e psicogênicos revoluciona as maneiras de analisar o Estado e o desenvolvimento do seu arcabouço institucional, e toda reflexão sobre os agentes que dele fazem parte, entendendo os mesmos como entrelaçados em redes de interdependência.

A interdependência, em Elias, não considera o indivíduo como algo exterior à sociedade, nem considera a sociedade como entidade exterior ao indivíduo ${ }^{10}$. A sociologia das relações de poder em Elias, demonstrada em obras como "A sociedade de corte", assinala que as relações sociais mais profundas estabelecidas entre os indivíduos singulares formam-se através de figurações. Este conceito refere-se a Redes ou cadeias de interdependências entre indivíduos em formas estruturais específicas, como a família, a escola, o exército, o Estado, etc. As figurações se modificam ao longo do tempo e são constituídas por indivíduos, "que se ligam, voluntária e involuntariamente, por meio de suas inclinações e necessidades" "11.

\footnotetext{
${ }^{7}$ ELIAS, Norbert. O processo civilizador volume 2: Formação do Estado e Civilização. Rio de Janeiro: Zahar, 1994b.

${ }^{8}$ Ibid., p. 196.

${ }^{9}$ Ibid., p. 198.

${ }^{10}$ CORCUFF, Philippe. As Novas Sociologias, op. cit., p.31.

${ }^{11}$ RIBEIRO, Luci Silva. Processo e figuração: um estudo sobre a Sociologia de Norbert Elias, op. cit., p. 165.
} 
Dadas estas considerações, o indivíduo, em Elias, possui ações conscientes e inconscientes, por vezes tem autonomia de ação e margens de escolha individual e por outras não as possui. Outra característica importante de sua obra refere-se à demonstração de constrangimentos exteriores da sociedade sobre as ações dos indivíduos, como também a subjetivação que as interdependências entre os indivíduos provocam nas estruturas internas da personalidade dos indivíduos através do conceito de autocontrole, no qual o indivíduo incorpora as estruturas coletivas nos seus âmbitos íntimos ${ }^{12}$. A partir da perspectiva teórica de Norbert Elias, as ações dos indivíduos dependem de uma rede de relações que existem antes do seu nascimento. As posições que ele ocupará dependerão dos laços familiares e da classe social das gerações anteriores, que irão influenciar sua escolarização, suas marcas simbólicas e sua personalidade ${ }^{13}$.

\section{A sociologia do poder em Norbert Elias e a formação do Estado Moderno}

Tendo como referência as considerações apontadas anteriormente, nesta seção nos dedicaremos a algumas contribuições de Norbert Elias para a sociologia do poder. O poder em Norbert Elias é relacional, envolvido por múltiplas lutas entre agentes e grupos em relações de força, prestígio e legitimidade, nas quais ocorrem regulações de conduta, de pulsões e emoções. O poder também possui um atributo estrutural, que permeia todas as relações humanas, tais como as familiares, as políticas, as econômicas e as religiosas ${ }^{14}$. Outra característica da sociologia do poder é o aspecto configuracional, na qual entendese que a estrutura social, composta de elementos interdependentes, está em constante transformação. Esta noção desalinha divisões entre o público e o privado, entre o social e o psíquico $^{15}$.

A sociologia do poder para Norbert Elias leva em conta a análise do longo processo civilizador nas sociedades ocidentais, realizado nas suas obras sobre sociologia histórica. Com a complexificação das sociedades produzida pelo longo processo civilizador, "o aparato sociogênico de autocontrole individual torna-se também mais diferenciado,

\footnotetext{
${ }^{12}$ CORCUFF, Philippe. As Novas Sociologias, op. cit., p. 34.

${ }^{13}$ COSTA, André. Norbert Elias e a configuração: um conceito interdisciplinar. In: Configurações, v. 19, p. 34-48, 2017, p. 43.

${ }^{14}$ Ibid., p. 45.

${ }^{15}$ Ibid., p. 37.
} 
complexo e estável" "16. Tal autocontrole está relacionado à monopolização da força física, à centralização e à estabilização da sociedade.

Norbert Elias relaciona a formação do Estado moderno como uma etapa do processo civilizador. Na medida em que as sociedades contam com estados que monopolizam e estabilizam a força física, o "comportamento e a constituição afetiva das pessoas mudam"17, sendo os mesmos protegidos contra os ataques súbitos exteriores e violências físicas contra a sua própria vida, forçando-se também a reprimir em si impulsos emocionais para atacar fisicamente outras pessoas. As cadeias de ações que ligam os indivíduos uns aos outros está interligada com a complexificação da divisão de funções e dependência mútua que os apertam em teias de interdependências mútuas. O crescimento das interdependências está relacionado ao aumento da diferenciação social em diferentes esferas, (econômicas, políticas, científicas, culturais, etc), relacionadas entre si, aumentando a complexidade da integração social (laços de obrigação e controle que reúnem os indivíduos em sociedade ${ }^{18}$.

Elias defende a ideia de que ocorre uma mudança civilizadora no comportamento dos indivíduos no processo de formação e consolidação do Estado, ocorrendo a "moderação de emoções espontâneas, o controle dos sentimentos, a ampliação do espaço mental"19, no qual os indivíduos levam em conta além do presente, o passado e o futuro, ligando os fatos em cadeias de causa e efeito.

Há uma mudança no aparato psicogênico e sociogênico dos príncipes e dos súditos com a monopolização da força física proporcionada pelo aparato estatal. Elias defende que antes do Estado, a violência era uma ocorrência recorrente e inescapável, sendo as cadeias de dependência entre os indivíduos de baixa extensão e a moderação das pulsões e afetos desnecessários, visto que a violência extrema, o ódio na destruição dos hostis e a paixão sem limites faziam parte da personalidade dos cavaleiros nobres. Com a monopolização da força física e a concentração de armamentos e exércitos sob o mando de uma única autoridade, "a ameaça física ao indivíduo lentamente se despersonaliza" 20.

Neste momento em que ocorre uma intensificação das teias de interdependência que ligam o rei em relação à nobreza, no qual a espada foi substituída pela intriga e pelos conflitos, através da pressão, do controle e da força que as pessoas passaram a exercer

\footnotetext{
${ }^{16}$ ELIAS, Norbert., op. cit., p.197.

${ }^{17}$ ELIAS, Norbert., op. cit., p. 198.

${ }^{18}$ RIBEIRO, Luci Silva., op. cit., p.117.

${ }^{19}$ ELIAS, Norbert., op. cit., p. 198.

${ }^{20}$ ELIAS, Norbert., op. cit., p.199.
} 
umas sobre as outras ${ }^{21}$. Deste modo, a interdependência está relacionada aos vínculos coercitivos que se impõem entre indivíduos, figurações e estruturas sociais. A segurança proporcionada pela centralização e estabilização do aparelho estatal cobrou seu preço, através da repressão dos impulsos emocionais individuais de ataques físicos de um indivíduo em relação ao outro ${ }^{22}$.

Nas classes superiores, a vigilância de um indivíduo sobre a conduta do outro ocorre de maneira mais coercitiva. O sucesso social do indivíduo de corte na etapa do processo civilizador que corresponde à formação do Estado moderno depende da reflexão contínua, da capacidade de previsão e cálculo, do autocontrole, da regulação das próprias emoções e do conhecimento do terreno onde as ações se desenrolam ${ }^{23}$. Os agentes políticos precisam necessariamente calcular as suas ações, estabelecendo uma expectativa dos sentimentos que os governados possuem em relação à sua pessoa.

Sua obra oferece aos leitores exemplos valiosos de pesquisa empírica e histórica que relacionam o indivíduo e a sociedade pensando-os através da interdependência, ensaiando a superação da dicotomia existente entre ambos. A ideia de que os indivíduos estão emaranhados em uma rede de interdependência, são dotados de emoções e praticantes de ações que fazem sentido no contexto no qual estão inseridos é uma importante chave para a sociologia do poder.

Outra obra de Elias que se dedica à sociologia do poder é "A Sociedade de Corte". Nas classes superiores, a vigilância de um indivíduo sobre a conduta do outro ocorre de maneira mais coercitiva. É nesse sentido que Elias toma por objeto a corte francesa nesta obra, pois um dos principais objetos de análise histórica nas sociedades ocidentais é a análise das suas respectivas cortes. As mesmas, em grande proporção, geraram sentidos de nação que marcam os imaginários coletivos que tentam explicar o que os habitantes de determinados territórios são e como os mesmos se constituíram.

Nas sociedades cortesãs, as relações pessoais e estatais confundem-se, daí a necessidade do estudo das relações de amizades e inimizades entre os indivíduos, bem como as alianças e rivalidades entre as famílias, a etiqueta, o cerimonial, as estruturas de habitação, entre outros aspectos que fazem parte dos "bastidores do poder" dizem respeito às relações sociais mais profundas estabelecidos entre os indivíduos singulares que formam entre si figurações diversas interligados por laços de interdependência. Tais

${ }^{21}$ ELIAS, Norbert., op. cit., p. 225.

${ }^{22}$ ELIAS, Norbert., op. cit., p. 198.

${ }^{23}$ ELIAS, Norbert., op. cit., p. 226. 
indivíduos possuem espaços para decisões individuais e também possuem limitações às suas decisões, devido à cadeia de reciprocidades e interdependências estabelecidos com os outros indivíduos que formam o tecido social. Um personagem histórico como Luís XIV é pensado a partir desta perspectiva na obra de Elias, e permite que os pesquisadores influenciados por sua obra analisem os sujeitos históricos e suas trajetórias de uma maneira que não tomem os indivíduos ora de uma maneira isolada, sem relação com os demais indivíduos, ou ora de maneira em que só se ocupem dos sistemas sociais, sem a possibilidade de pensar a singularidade dos indivíduos. O mesmo vale para os analistas sociais que se dedicam ao estudo do poder e da política, nas relações entre os indivíduos e as instituições sociais.

Um aspecto interessante na obra de Elias é o reconhecimento de que o processo civilizador que provoca o controle das emoções por parte dos indivíduos interligados por elos de interdependência acontece com tenuidades, avanços e recuos: "o processo civilizador, a despeito da transformação e aumento das limitações que impõe as emoções, é acompanhado permanentemente por tipos de libertação dos mais diversos"24.

Uma dessas tenuidades se refere à mulher na sociedade de corte. Esta tem grande poder nesta sociedade, se comparada à sociedade burguesa, por exemplo, pois a mesma possui máscaras, leques e disfarces ${ }^{25}$, com um grau de espontaneidade e possibilidade de articulação nas figurações que desempenha na sociedade em que se encontra. Quando Elias analisa a disposição dos quartos do palácio real diziam respeito à posição, poder e prestígio do rei ${ }^{26}$, ele também o faz em relação ao quarto da rainha. Os rituais de despertar do rei e da rainha e a participação dos outros indivíduos que faziam parte da sua família e da corte nas suas intimidades são reflexos da posição social não apenas do rei, como também destas mesmas pessoas partícipes dos rituais, e deu à rainha liberdade ante ao rei. À mulher cortesã, o mesmo acontecia. No casamento nas sociedades absolutistas, verificava-se quase a igualdade das mulheres perante aos homens, inclusive quanto às relações extraconjugais:

"O poder social da esposa e quase igual ao do marido. A opinião social é formulada, em alto grau, pelas mulheres. E, se a sociedade até então aceitara apenas as relações extraconjugais dos homens, considerando as do "sexo [socialmente] mais fraco" como mais ou menos

\footnotetext{
${ }^{24}$ ELIAS, Norbert. O processo civilizador volume 1: Uma História dos Costumes. Rio de Janeiro: Zahar, 1994 a, p. 184.

${ }^{25}$ ELIAS, Norbert. A Sociedade de Corte: Investigação sobre a Sociologia da Realeza e da Aristocracia de Corte. Rio de Janeiro: Zahar, 2001a, p. 245.

${ }^{26}$ ELIAS, Norbert., op. cit., p. 99.
} 
repreensíveis, essas relações por parte das mulheres parecem nesse momento, dentro de certos limites devido à mudança no equilíbrio de poder entre os sexos, como legítimas"27.

A comparação sócio histórica entre o poder das mulheres nas sociedades de corte e o poder das mulheres nas sociedades burguesas é um interessante exercício analítico para o entendimento do poder político feminino nas sociedades atuais, herdeiras do padrão burguês de dominação política.

\section{A sociologia do poder em Norbert Elias a partir de um estudo de uma pequena comunidade}

A produção sociológica de Norbert Elias contempla análises das dinâmicas de poder em sociedades de uma maneira ampla, espacial e temporalmente, e também a partir de uma perspectiva de análise a partir de pequenas comunidades, como é o caso da obra "Os estabelecidos e os outsiders: Sociologia das relações de poder a partir de uma pequena comunidade". Escrito juntamente com o seu assistente de pesquisa, John Scotson, este livro é resultado de uma pesquisa que foi realizada no final dos anos $50 \mathrm{em}$ uma pequena comunidade batizada com o nome fictício de "Winston Parva". A análise desta comunidade foi resultado de um trabalho de campo que durou aproximadamente três anos, que também reuniu estatísticas oficiais, relatórios governamentais, documentos jurídicos e jornalísticos, entrevistas e, principalmente, "observação participante"28.

O livro busca uma explicação sociológica da desigualdade em uma pequena comunidade, relativamente homogênea, pois não havia grandes diferenças de nacionalidade, etnia, ocupação, renda ou classe social. A única diferença entre as pessoas era o fato da existência de dois grupos de moradores, um composto de antigos residentes, "estabelecidos" há duas ou três gerações, e os "outsiders", recém-chegados à comunidade $^{29}$. O primeiro grupo agia coercitivamente sobre o segundo grupo com o foco na perpetuação das desigualdades através da estigmatização e inferiorização, individuais e grupais ${ }^{30}$.

\footnotetext{
${ }^{27}$ ELIAS, Norbert. O processo civilizador volume 1, p. 183.

${ }^{28}$ NEIBURG, Federico. Apresentação à edição brasileira: A sociologia das relações de poder de Norbert Elias. In: ELIAS, Norbert; SCOTSON, John. Os estabelecidos e os outsiders- Sociologia das relações de poder a partir de uma pequena comunidade. Rio de Janeiro: Zahar, 2000, p. 9.

${ }^{29}$ ELIAS, Norbert; SCOTSON, John. Os estabelecidos e os outsiders- Sociologia das relações de poder a partir de uma pequena comunidade. Rio de Janeiro: Zahar, 2000, p. 21.

${ }^{30}$ ELIAS, Norbert; SCOTSON, John., op. cit., p. 22-23.
} 
O objetivo do livro é analisar características de uma figuração universal em pequena comunidade, de modo que os problemas de estigmatização e reprodução de desigualdades sociais são recorrentes em várias unidades sociais, sejam elas simples e menores, ou maiores e mais diferenciadas ${ }^{31}$. A perspectiva da reprodução das desigualdades sociais se desenrola com a seguinte dinâmica:

"Um grupo só pode estigmatizar outro com eficácia quando está bem instalado em posições de poder das quais o grupo estigmatizado é excluído. Enquanto isso acontece, o estigma de desonra coletiva imputado aos outsiders pode fazer-se prevalecer" ${ }^{\prime 32}$.

O sentimento de desonra pelos "outsiders" é grupal e compartilhado. Os dominados, nessa dinâmica, oferecem condições para a reprodução das altas posições aos grupos dominantes. Ambos grupos nutrem auto-representações de depreciação grupal (outsiders) e honra coletiva (estabelecidos). O quadro a seguir sintetizará a auto representação dos grupos de "estabelecidos" e "outsiders", pormenorizados na obra em questão:

\begin{tabular}{|c|c|}
\hline Estabelecidos & Outsiders \\
\hline Grupos poderosos & Grupos sem poder \\
\hline Humanamente superiores & Humanamente inferiores \\
\hline Aristocratas & Vilões \\
\hline Dominação dos melhores & Dominados pelos melhores \\
\hline Alto valor humano & Baixo valor humano \\
\hline Moral Alta & Moral baixa \\
\hline Normativos/nômicos & Anômicos \\
\hline Bons & Ruins \\
\hline Lança o estigma sobre o outro grupo & Incorpora coletivamente o estigma \\
\hline Carisma grupal & Desonra grupal \\
\hline $\begin{array}{l}\text { Preservam superioridade evitando o } \\
\text { contato com os outsiders- "medo da } \\
\text { poluição"/contaminação }\end{array}$ & $\begin{array}{l}\text { Podem transmitir inferioridade para os } \\
\text { estabelecidos quando entram em contato } \\
\text { com eles }\end{array}$ \\
\hline $\begin{array}{c}\text { Dignos de confiança, disciplinados e } \\
\text { ordeiros }\end{array}$ & $\begin{array}{c}\text { Indignos de confiança, indisciplinados e } \\
\text { desordeiros }\end{array}$ \\
\hline Limpeza & Sujeira \\
\hline Inclusão "nós" & Exclusão "eles" \\
\hline Alta coesão e intimidade emocional & Baixa coesão e intimidade emocional \\
\hline $\begin{array}{l}\text { Esforçam-se em manter a posição, } \\
\text { depreciando quem pode ameaça-los }\end{array}$ & $\begin{array}{l}\text { Empenham-se em melhorar a condição, } \\
\text { elevando-se do status inferior }\end{array}$ \\
\hline Impõem crenças depreciativas & Internalizam crenças depreciativas \\
\hline
\end{tabular}

Quadro: Elaboração da autora. Informações disponíveis em ELIAS; SCOTSON, 2010.

${ }^{31}$ ELIAS, Norbert; SCOTSON, John., op. cit., p. 20.

${ }^{32}$ ELIAS, Norbert; SCOTSON, John., op. cit., p. 23. 
Esta análise assinala algumas formas simbólicas e subjetivas de dominação e reprodução das desigualdades sociais, que não necessariamente são de classe ou renda. Este diálogo crítico com a teoria marxista, Norbert Elias assinala que as desigualdades observadas entre os "outsiders" são relacionadas não ao aspecto material, mas ao aspecto simbólico de dominação e depreciação do grupo dominante em relação ao grupo dominado. As tensões entre estes dois grupos também possuem correspondência com a ideia de que os recém-chegados à comunidade eram vistos como ameaças aos antigos moradores. Estes constituíam uma ordem social estabelecida e coesa, com alta coerção e vigilância interna, uma contraposição ao grupo de recém-chegados, hostilizados e depreciados com o objetivo de mantê-los neste estado de exclusão para a continuidade da dominação social e afirmação positiva da identidade do grupo dos antigos moradores, estabelecidos na comunidade há algumas gerações.

\section{Conclusão}

A sociologia do poder em Norbert Elias possui grande contribuição para a análise social e histórica, em termos estruturais e nas relações de pequenas comunidades. Sua obra é extremamente importante para a sociologia contemporânea, proporcionando possibilidades arrojadas para a tentativa de superação da separação radical entre o subjetivismo e o objetivismo, oferecendo importantes contribuições para a compreensão relacional do indivíduo e da sociedade.

A obra de Norbert Elias indica às análises políticas que o as ações individuais dos agentes do poder não são planejadas intencionalmente de maneira isolada, nem ocorrem de maneira caótica, e sim são frutos da interdependência entre os indivíduos entrelaçados em um contexto de permanente movimento de forças de renovação e conservação. Isso leva a uma análise que não considera os políticos isolados, e sim relacionados a uma cadeia de dependências mútuas entre eles e os indivíduos pertencentes às instituições como a família, a igreja, o Estado, etc. O desenvolvimento destas instituições provoca mudanças estruturais e emocionais, que visam o controle de impulsos e estratégias de manutenção das posições sociais. As relações e posições ocupadas pelos indivíduos são exteriores a ele e determinadas por uma rede de relações que existem anteriormente a ele, daí a importância da análise social a partir da perspectiva de heranças e laços familiares que muitas vezes determinam a posição que o indivíduo ocupará na estrutura social. 
A sociologia do poder em Norbert Elias permite pensá-lo de maneira relacional, estrutura, e configuracional, tal como foi apontado nas seções deste trabalho. Pensar o poder também nos leva a reflexão histórica e estrutural das instituições e dos indivíduos e grupos inseridos nessas cadeias de interdependências, tal como aponta obras como "O Processo Civilizador" e "A sociedade de corte". O estudo das relações de poder elisiano proporciona a reflexão sobre questões como as regras de etiqueta, cerimonial, ritual relações de gênero, entre outras, de maneira histórica e comparativa. A obra de Elias possui relevância extrema para análises metodológicas e teóricas sobre o poder.

\section{Referências}

CORCUFF, Philippe. As Novas Sociologias: Construções da realidade sociais. Queluz: Editora Vral, 2001.

COSTA, André. Norbert Elias e a configuração: um conceito interdisciplinar. In: Configurações, vol.19, 2017, p. 34-48.

ELIAS, Norbert. A Sociedade de Corte: Investigação sobre a Sociologia da Realeza e da Aristocracia de Corte. Rio de Janeiro: Zahar, 2001.

ELIAS, Norbert. O processo civilizador volume 1: Uma História dos Costumes. Rio de Janeiro: Zahar, 1994a.

ELIAS, Norbert. O processo civilizador volume 2: Formação do Estado e Civilização. Rio de Janeiro: Zahar, 1994b.

ELIAS, Norbert. A Sociedade de Corte: Investigação sobre a Sociologia da Realeza e da Aristocracia de Corte. Rio de Janeiro: Zahar, 2001a.

ELIAS, Norbert. Norbert Elias por ele mesmo. Rio de Janeiro: Zahar, $2001 \mathrm{~b}$.

ELIAS, Norbert; SCOTSON, John. Os estabelecidos e os outsiders- Sociologia das relações de poder a partir de uma pequena comunidade. Rio de Janeiro: Zahar, 2000.

NEIBURG, Federico. Apresentação à edição brasileira: A sociologia das relações de poder de Norbert Elias. In: ELIAS, Norbert; SCOTSON, John. Os estabelecidos e os outsiders- Sociologia das relações de poder a partir de uma pequena comunidade. Rio de Janeiro: Zahar, 2000.

RIBEIRO, Luci Silva. Processo e figuração: um estudo sobre a Sociologia de Norbert Elias. Tese. Doutorado em Sociologia. Universidade de Campinas, 2010.

RIBEIRO, Renato Janine. Apresentação a Norbert Elias. In: ELIAS, Norbert. O processo civilizador. Rio de Janeiro: Zahar, 1994. 